\title{
IDEOLOGIA DE GÊNERO: UMA FALÁCIA CONSTRUÍDA SOBRE OS PLANOS DE EDUCAÇÃO BRASILEIROS
}

\author{
Toni ReIs ${ }^{1}$ \\ EdLA EGGERT ${ }^{2}$
}

\begin{abstract}
RESUMO: Este artigo explora uma falácia, chamada "ideologia de gênero", que aflorou nas discussóes sobre os atuais Planos de Educação. Revisita os principais marcos internacionais e nacionais surgidos desde 1948 relativos aos direitos humanos, à educação, à igualdade de gênero e à erradicação da discriminação e violência motivadas por gênero, orientação sexual e identidade de gênero. Examina argumentos de segmentos reacionários e/ou acríticos da sociedade contra a inclusáo desses temas nos Planos. Conclui apontando para a necessidade do envolvimento de outros setores a fim de diminuir o enviesamento e contribuir para que a Educação brasileira incorpore a igualdade de gênero e o respeito à diversidade sexual.
\end{abstract}

Palavras-chave: Educação. Planos de Educação. Gênero. Diversidade sexual.

\section{GENDER IDEOLOGY: A FALLACY BUILT AROUND THE BRAZILIAN EDUCATION PLANS}

ABSTRACT: This article explores a fallacy, known as "gender ideology", that came to the surface in the discussions about the current Education Plans. It revisits international and national frameworks arising since 1948 on human rights and education, gender equality and the eradication of discrimination and violence based on gender, sexual orientation and gender identity. Arguments made by reactionary and/ or uncritical segments of society against the inclusion of these themes in the Education Plans are examined. The article concludes by pointing to the need for other sectors to become engaged in order to reduce bias and contribute towards Brazilian Education incorporating gender equality and respect for sexual diversity.

Keywords: Education. Education Plans. Gender. Sexual diversity.

\footnotetext{
${ }^{1}$ Universidade do Vale do Rio dos Sinos - São Leopoldo (RS), Brasil. E-mail: tonireisctba@gmail.com ${ }^{2}$ Pontifícia Universidade Católica do Rio Grande do Sul, Escola de Humanidades - Porto Alegre (RS), Brasil. E-mail: edla.eggert@gmail.com DOI: $10.1590 / E S 0101-73302017165522$
} 


\title{
L'IDEOLOGIE DU GENRE : UN SOPHISME CONSTRUit SUR LES PLANS D'ÉduCATION BRESILIENS
}

\begin{abstract}
RESUME : Cet article explore une erreur appelée 'idéologie du genre' qui a fait surface dans les discussions sur les plans d'éducation actuels. On revisite les principaux monuments nationaux et internationaux apparus depuis 1948 sur les droits de l'homme, l'éducation, l'égalité des sexes et l'élimination de la discrimination et la violence motivées par le sexe, l'orientation sexuelle et l'identité de genre. On examine des arguments de segments réactionnaires et / ou non critiques de la société contre l'inclusion de ces sujets dans les plans. Pour conclusion on souligne la nécessité de la participation d'autres secteurs afin de réduire les préjugés et contribuer à l'éducation brésilienne pour qu'elle intègre l'égalité des sexes et le respect de la diversité sexuelle.
\end{abstract}

Mots-clés : Education. Plans d'Éducation. Sexe. Diversité sexuelle.

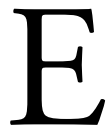

ste artigo contém forte relação com a experiência de militância na luta contra a homofobia e na participação nos debates sobre a Conferência Nacional de Educação Básica de 2008 e nas Conferências Nacionais de Educação de 2010 e 2014, assim como também no acompanhamento da elaboração do Plano Nacional de Educação (2014), do Plano Estadual de Educação do Paraná e do Plano Municipal de Educação de Curitiba (2015). Nesse contexto, uma parte do que escrevemos aqui envolve as vivências e também as percepçôes do fenômeno denominado "ideologia de gênero" na educação.

\section{Um pouco das memórias na luta por Educação para tod@s como Direito Fundamental}

A educação para todos e todas tem sido considerada um direito humano fundamental há tempo. A Declaração Universal dos Direitos Humanos, de 1948, estabelece que "todo ser humano tem direito à instrução [...] orientada no sentido do pleno desenvolvimento da personalidade humana e do fortalecimento do respeito pelos direitos humanos e pelas liberdades fundamentais" (ONU, 1948). Da mesma forma, a universalidade e a indivisibilidade dos direitos humanos também têm sido postas como preceitos pétreos, de modo que "todas as pessoas nascem livres e iguais em dignidade e direitos [...] sem distinçấo de qualquer espécie" (ONU, 1948).

Desde então foram construídos democraticamente e ratificados pelo Brasil diversos documentos e tratados internacionais que versam tanto sobre educação quanto sobre igualdade de direitos, entre os quais os citados a seguir se destacam em relação ao tema em discussão. 
A Convenção sobre a Eliminação de Todas as Formas de Discriminação contra as Mulheres (1979) estabelece especificamente no seu artigo $10^{\circ}$ que "Os Estados-partes adotarão todas as medidas apropriadas para eliminar a discriminação contra a mulher, a fim de assegurar-lhe a igualdade de direitos com o homem na esfera da educação" e também para eliminar "todo conceito estereotipado dos papéis masculino e feminino em todos os níveis e em todas as formas de ensino..." (UNICEF, 1979).

No ano 2000, o Fórum Mundial de Educação adotou o Compromisso de Dakar referente à Educação para Todos, com tendo entre suas metas a eliminação, até 2005, "das disparidades existentes entre os gêneros na educação primária e secundária e, até 2015 , atingir a igualdade entre os gêneros em educação" (UNESCO, 2001, p. 20).

$\mathrm{O}$ artigo $8^{\circ}$ da Convençáo Interamericana para Prevenir, Punir e Erradicar a Violência contra a Mulher, de 1994, estabelece que os Estados Partes adotarão, progressivamente, medidas específicas, inclusive programas formais e não formais de educação destinados a:

combater preconceitos e costumes e todas as outras práticas baseadas na premissa da inferioridade ou superioridade de qualquer dos gêneros ou nos papéis estereotipados para o homem e a mulher, que legitimem ou exacerbem a violência contra a mulher (OEA, 1994).

Entre as áreas prioritárias destacadas pela Plataforma de Ação da Conferência Mundial sobre as Mulheres (1995), tem-se a desigualdade no acesso à educação e à capacitação, e a necessidade de proteção e promoção voltadas especificamente para os direitos da menina (UNFPA, 1995).

Em 2015, foram estabelecidos os Objetivos de Desenvolvimento Sustentável para serem alcançados até 2030. O item 5 do Objetivo 4 prevê a eliminação das "disparidades de gênero na educação", enquanto o Objetivo 5 deseja "alcançar a igualdade de gênero e empoderar todas as mulheres e meninas" (PNUD, 2015).

Também no Século XXI, começou a se consolidar o entendimento de que são direitos humanos não somente a equidade de gênero como também a livre orientação sexual e identidade de gênero. Da mesma forma, as violências praticadas por motivo de orientaçáo sexual e identidade de gênero podem ser consideradas violências de gênero (BORRILLO, 2009 apud BRASIL, 2012a, p. 8).

No que diz respeito à educação, os Princípios de Yogyakarta sobre a Aplicação da Legislação Internacional de Direitos Humanos em Relação à Orientação Sexual e Identidade de Gênero (2007) afirmam que "Toda pessoa tem o 
direito à educação, sem discriminação por motivo de sua orientação sexual e identidade de gênero, e respeitando essas características" (Princípios de Yogyakarta, 2007, p. 23), e aponta oito deveres dos Estados nesse sentido, incluindo acesso igual à educação e tratamento igual, desenvolvimento do respeito aos direitos humanos, proteção adequada contra exclusão, violência e discriminação (Princípios de Yogyakarta, 2007).

Tanto a Organização das Naçóes Unidas (ONU) quanto a Organização dos Estados Americanos (OEA) têm aprovado declaraçóes e resoluçóes afirmando que a orientação sexual e a identidade de gênero também devem ser consideradas como direitos humanos (ONU, 2008; OEA, 2008). Como parte desse processo, em 2013, a ONU publicou recomendaçóes para os Estados referentes às principais obrigaçóes que estes têm para com lésbicas, gays, bissexuais, travestis e transexuais (pessoas LGBT), incluindo a proteção contra a violência homofóbica e transfóbica, e a proibição da discriminação com base na orientação sexual e identidade de gênero. (UNITED NATIONS, 2013, p. 13).

Nesse sentido, a questão da orientação sexual e da identidade de gênero também ingressa no campo dos direitos humanos e, por conseguinte, no campo da educação. Isso se encontra refletido em legislaçóes federais brasileiras recentes. O Estatuto da Juventude tem uma seção específica sobre o Direito à Diversidade e à Igualdade, que determina que o jovem não será discriminado inclusive por motivo de sexo e orientação sexual (BRASIL, 2013a), e que para a efetivação do direito do jovem à diversidade e à igualdade a ação do poder público deverá incluir

[...] temas sobre questóes étnicas, raciais, de deficiência, de orientaçáo sexual, de gênero e de violência doméstica e sexual praticada contra a mulher na formação dos profissionais de educação, de saúde e de segurança pública e dos operadores do direito. (BRASIL, 2013a, grifos nossos).

Os desdobramentos dos documentos e tratados internacionais citados acima, entre outros, têm tido reflexos na legislação nacional, a começar pela Constituição Federal de 1988, que inclusive prevê a construção de uma sociedade livre, justa e solidária, a redução das desigualdades sociais e regionais, e a promoção do bem de todos, sem preconceitos de origem, raça, sexo, cor, idade e quaisquer outras formas de discriminação (BRASIL, 2008a).

Outros exemplos encontrados na legislação nacional incluem a Lei Maria da Penha (BRASIL, 2006a) e as políticas públicas federais, como os Planos Nacionais de Políticas para as Mulheres (BRASIL, 2006b; 2008b; 2013b), e o Plano Nacional de Promoção da Cidadania e dos Direitos Humanos de LGBT (BRASIL, 2009), entre outros tantos exemplos. Os dois Planos contêm diversas 
metas e açóes voltadas para o alcance de uma educação pública que promova a equidade de gênero e o respeito à diversidade sexual, apesar de ainda estarem longe de serem cumpridas.

Os Planos acima citados foram construídos a partir de Conferências sociais específicas que tiveram etapas municipais, estaduais e nacionais, envolvendo democraticamente todas as partes interessadas, e cujas deliberaçóes vieram a ser sistematizadas nos Planos. Da mesma forma, o próprio setor da educação realizou a Conferência Nacional da Educação Básica - Coneb (2008) e as Conferências Nacionais de Educação - Conae (2010 e 2014), também com as respectivas etapas municipais e estaduais.

O Documento Final da Coneb registra que durante toda a Conferência e na plenária final houve destaque para "uma educação com qualidade social que [...] vise à superação das desigualdades sociais, raciais, de gênero, de idade e de orientação sexual" (BRASIL, 2008c, p. 1).

O Documento Final da Conae 2010 também se encontra permeado de referências a gênero, diversidade sexual, orientação sexual e identidade de gênero, inclusive com deliberaçóes aprovadas sobre gênero e diversidade sexual, como esta:

b) Inserir e implementar na política de valorização e formação dos/das profissionais da educaçáo, a partir da reorganização da proposta curricular nacional, a discussão de gênero e diversidade sexual, na perspectiva dos direitos humanos, quebrando os paradigmas hoje instituídos e adotando para o currículo de todos os cursos de formação de professores/as um discurso de superação da dominaçáo do masculino sobre o feminino, para que se afirme a constituição de uma educação não sexista. (BRASIL, 2010, p. 143).

Em 2012, foram homologadas as Diretrizes Nacionais para a Educação em Direitos Humanos. Fazem diversas referências a gênero e à orientação sexual e afirmam que todas as pessoas devem ter a possibilidade de usufruírem de uma educação não discriminatória e democrática, independente do seu sexo, orientaçáo sexual e identidade de gênero, entre outras características. (BRASIL, 2012b, p. 2).

No mesmo ano, as Diretrizes Curriculares Nacionais para o Ensino Médio determinaram que, em função da legislação específica existente, é obrigatória a educação em direitos humanos (BRASIL, 2012c, art. 10), e que o projeto político-pedagógico do Ensino Médio deve considerar:

XV - valorização e promoção dos direitos humanos mediante temas relativos a gênero, identidade de gênero, raça e etnia, religiaáo, orientação sexual, pessoas com deficiência, entre outros, 
bem como práticas que contribuam para a igualdade e para o enfrentamento de todas as formas de preconceito, discriminação e violência. (BRASIL, 2012c, art. 16).

Do exposto acima, fica evidenciado que vem tendo um processo, há décadas, internacional e nacionalmente, voltado para a promoção da equidade entre os gêneros e para o respeito à diversidade sexual, no qual o papel da educação é visto como essencial para se atingir esse objetivo.

Especificamente no Brasil, a promoção da educação em prol da equidade de gênero e do respeito à diversidade sexual torna-se ainda mais importante quando se consideram as estatísticas sobre violências e discriminaçóes baseadas em gênero, orientação sexual e identidade de gênero.

Segundo o Mapa da Violência 2015, entre 1980 e 2013 foram assassinadas no país 106.093 mulheres. Desde 2008, mais de 4 mil mulheres são assassinadas por ano no Brasil, com tendência crescente (WAISELFISZ, 2015).

O Relatório sobre Violência Homofóbica no Brasil: ano de 2012, publicado pela Secretaria de Direitos Humanos da Presidência da República, revela que naquele ano houve 9.982 denúncias de violaçóes dos direitos humanos de pessoas LGBT, bem como pelo menos 310 homicídios de LGBT no país. É um quadro que se repete todos os anos (BRASIL, 2013c).

A organização não governamental europeia, Transgender Europe, monitora os assassinatos de travestis e transexuais registrados e noticiados mundialmente. Segundo a entidade, entre 2008 e 2014, o Brasil liderou o ranking mundial de assassinatos, com mais de 600 travestis e transexuais mortos, seguido do México, com menos de 200 no mesmo período. (TRANSGENDER EUROPE, 2015).

Entre diversos estudos sobre preconceito e discriminação em estabelecimentos educacionais, pesquisa nacional publicada em 2009 revelou que o nível de atitudes preconceituosas foi de $93,5 \%$ em relação a gênero e $87,3 \%$ em relação à orientação sexual (MAZZON, 2009, p. 12), e que o grau de conhecimento de práticas discriminatórias sofridas por estudantes foi de $10,9 \%$ por ser mulher e $17,4 \%$ por ser homossexual (MAZZON, 2009, p. 19).

\section{Os planos de Estado para a educação versus a ideologia de gênero}

Retomando a discussão da importância da educaçáo como resposta a esse quadro, a Lei de Diretrizes e Bases da Educação Nacional (LDB) de 1996 estabeleceu a elaboração pela União de um plano decenal, em colaboração com os Estados, o Distrito Federal e os Municípios, que estivesse em sintonia com a Declaração Mundial sobre Educação para Todos de 1990 (BRASIL, 1996). Des- 
sa forma, em cumprimento das disposiçóes da LDB, o primeiro Plano Nacional de Educação (PNE) foi elaborado e vigorou entre 2001 e 2010.

As deliberações da Coneb de 2008 e da Conae de 2010 foram vistas, portanto, como se constituindo "em marco para a construção de um novo Plano Nacional de Educação com ampla participação das sociedades civil e política" (BRASIL, 2010, p. 14), uma vez que o primeiro PNE estava chegando ao fim na época.

A proposta do novo PNE foi apresentada na Câmara dos Deputados em 20 de dezembro de 2010. Após quase dois anos de debates e tramitação, a redação final aprovada pela Câmara dos Deputados e encaminhada para o Senado contemplou as deliberaçóes das Conferências Nacionais de Educação sobre equidade de gênero e o respeito à diversidade sexual de duas formas principais. $\mathrm{O}$ artigo $2^{\circ}$ estabeleceu que "São diretrizes do PNE [...] III - a superação das desigualdades educacionais, com ênfase na promoção da igualdade racial, regional, de gênero e de orientação sexual e na erradicação de todas as formas de discriminação" (BRASIL, 2012d). Segundo, em toda a redação foi utilizada flexão de gênero, por exemplo, os/as profissionais da educação, indicando claramente a intenção do Plano em ser um instrumento de promoção da sensibilização quanto à equidade de gênero, deixando de se referir às pessoas apenas no masculino.

Em 17 de dezembro de 2013, o Plenário do Senado aprovou o Substitutivo ao Projeto de Lei, no qual retirou da redação do inciso III do artigo $2^{\circ}$ a frase "promoção da igualdade racial, regional, de gênero e de orientação sexual" (BRASIL, 2013d). Também suprimiu, em todo o texto, a flexão de gênero, adotando a forma genérica masculina (BRASIL, 2013d).

De volta na Câmara dos Deputados, aflorou-se de vez nas audiências e debates sobre o Projeto de Lei o fenômeno da "ideologia de gênero", com calorosas manifestaçóes pró e contra, até sua sanção presidencial em 25 de junho de 2014, com flexão de gênero, porém sem especificação de formas de discriminação (BRASIL, 2014).

Mas o que seria então, primeiramente, ideologia? Entre suas várias definiçóes, ideologia pode ser considerada como uma "maneira de pensar que caracteriza um indivíduo ou grupo de pessoas" (MICHAELIS, 1998). Outro significado atribuído ao termo ideologia é o de uma "doutrina mais ou menos destituída de validade objetiva, porém mantida pelos interesses claros ou ocultos daqueles que a utilizam” (ABBAGNANO, 2003, p. 521).

Em Marx e Engles, ideologia tem o sentido de um meio utilizado pela classe dominante para manter seu domínio sobre as demais classes por meio da imposição de suas ideias. Nessa perspectiva, a ideologia também é vista como uma consciência falsa existente entre quem é dominado e que mascara e inverte a realidade social em que se encontram para os ideais da classe dominante (MARX; ENGELS, 1997). 
E por que misturar gênero com ideologia?

Um dos autores que tem propagado o conceito de ideologia de gênero vista a partir da ótica de imposição de ideias é o argentino Jorge Scala, em especial por meio de palestras e do livro intitulado Ideologia de Gênero: o neototalitarismo e a morte da família (SCALA, 2015). Em entrevista concedida em 2012 e disponível na internet, Scala define ideologia da seguinte forma:

Uma ideologia é um corpo fechado de ideias, que parte de um pressuposto básico falso - que por isto deve impor-se evitando toda análise racional, e entáo vão surgindo as consequências lógicas desse princípio falso. As ideologias se impōem utilizando o sistema educacional formal (escola e universidade) e não formal (meios de propaganda), como fizeram os nazistas e os marxistas. (SCALA, 2012)

$\mathrm{Na}$ entrevista, Scala afirma que escreveu o livro sobre ideologia de gênero porque

a ONU criou uma Agência do Gênero. Essa agência se dedica a controlar que todos os organismos e programas da ONU incluam o gênero. Por sua vez, a União Europeia e o Banco Mundial condicionam os empréstimos para o desenvolvimento dos países pobres, por cláusulas da difusão de Gênero. Finalmente, se incorporou o gênero no sistema educacional dos nossos países. Dado tudo isto, é necessário investigar o que é o gênero. (SCALA, 2012).

Vê-se nessa afirmaçáo o desdobramento dos acordos e tratados das Naçóes Unidas expostos acima, em especial a Declaração e Plataforma de Ação da IV Conferência Mundial sobre a Mulher (1995), porém visto com um olhar desfavorável pelo autor. Relevante citar a Plataforma de Ação, cujo item 27 afirma que "em vários países, as diferenças entre as realizaçóes e as atividades da mulher e do homem, ao invés de serem reconhecidas como consequência de funçōes socialmente estabelecidas para cada sexo, continuam sendo atribuídas a diferenças biológicas imutáveis" (UNFPA, 1995, p. 159).

Ao definir o que considera ser ideologia de gênero, na mesma entrevista Scala corrobora a constatação da Plataforma:

Seu fundamento [da ideologia de gênero] principal e falso é este: o sexo seria o aspecto biológico do ser humano, e o gênero seria a construçáo social ou cultural do sexo. Ou seja, que cada um seria absolutamente livre, sem condicionamento algum, nem sequer o biológico, para determinar seu próprio gênero, dando-lhe o conteúdo que quiser e mudando de gênero quantas vezes quiser. 
Agora, se isso fosse verdade, não haveria diferenças entre homem e mulher - exceto as biológicas; qualquer tipo de união entre os sexos seria social e moralmente boas, e todas seriam matrimônio; cada tipo de matrimônio levaria a um novo tipo de família; o aborto seria um direito humano inalienável da mulher, já que somente ela é que fica grávida; etc. Tudo isso é tão absurdo, que só pode ser imposto com uma espécie de "lavagem cerebral" global [...] O gênero destrói a estrutura antropológica íntima do ser humano... (SCALA, 2012).

No debate ocorrido em torno do Plano Nacional de Educação, e subsequentemente em torno dos Planos Municipais e Estaduais de Educaçáo, o termo ideologia de gênero foi utilizado por quem defende posiçóes tradicionais, reacionárias e até fundamentalistas em relação aos papéis de gênero do homem e da mulher, reiterando os posicionamentos de autores como Scala, afirmando que ideologia de gênero significa a desconstrução dos papéis tradicionais de gênero.

Artigo disponível na página da Conferência Nacional dos Bispos do Brasil (CNBB) expressa e divulga opinióes parecidas:

As expressôes "gênero" ou "orientação sexual" referem-se a uma ideologia que procura encobrir o fato de que os seres humanos se dividem em dois sexos. Segundo essa corrente ideológica, as diferenças entre homem e mulher, além das evidentes implicaçóes anatômicas, não correspondem a uma natureza fixa, mas são resultado de uma construção social. Seguem o célebre aforismo de Simone de Beauvoir: "Não se nasce mulher, fazem-na mulher (sic)". Assim, sob o vocábulo "gênero", é apresentada uma nova filosofia da sexualidade. (RIFAN, 2015)

Importante destacar que nenhum dos Documentos Finais das Conferências de Educação de 2008, 2010 e 2014, nem a versão inicial do Plano Nacional de Educação, fazem menção do termo "ideologia de gênero", e sim têm por objetivo garantir o alcance da equidade entre os gêneros e o respeito à diversidade sexual. Não obstante, os argumentos levantados por diversos setores contrários afirmam que esses documentos deliberaram pela inclusão da "ideologia de gênero e de diversidade sexual" nos Planos Estaduais e Municipais de Educação.

Retornando ao artigo no site da CNBB, o autor afirma que

Retirada do Plano Nacional de Educação no ano passado, a "Ideologia de Gênero" volta à carga de modo mais sutil: querem inserir essa perniciosa ideologia nos planos municipais e estaduais de educação. O MEC instrui as secretarias de educação de 
todos os municípios e Estados a inserir "gênero" e "orientação sexual" nos planos de educação, como critérios para a implementação de políticas educacionais. (RIFAN, 2015)

O Cardeal Arcebispo de São Paulo, Dom Odilo P. Scherer, foi ainda mais longe e afirmou que

\begin{abstract}
essa ideologia [de gênero] poderia abrir um caminho perigoso para a legitimação da pedofilia, uma vez que a orientação pedófila também poderia ser considerada um tipo de gênero (SCHERER, 2015).
\end{abstract}

Considerando as fontes citadas, percebe-se que se formou uma aliança composta por evangélicos e católicos mais ortodoxos, quando não fundamentalistas, bem como organizaçóes conservadoras/reacionárias que defendem o que chamam de família e costumes tradicionais, unidas em divulgar e disseminar informaçóes distorcidas para impedir que se alcance a equidade entre os gêneros e o respeito à diversidade sexual, conforme vem sendo ratificado internacional e nacionalmente há décadas com a intenção de diminuir as discriminaçóes e as violências baseadas em gênero.

O artigo publicado no site da CNBB afirma que "os que adotam o termo gênero não estão querendo combater a discriminação, mas sim 'desconstruir' a família, o matrimônio e a maternidade e, deste modo, fomentam um 'estilo de vida' que incentiva todas as formas de experimentação sexual desde a mais tenra idade".

Essa aliança entre setores geralmente não ligados entre si surtiu efeito. Segundo levantamento realizado em janeiro de 2016 pela iniciativa "De Olho nos Planos”, em relação aos 22 das 27 Planos Estaduais de Educação aprovados e sancionados na forma de lei, 9 não fazem qualquer referência à palavra "gênero" e 15 não explicitam o termo "gênero" nos Princípios ou Diretrizes do Plano ao citar o enfrentamento a toda forma de discriminação (DE OLHO NOS PLANOS, 2016).

Tanto o próprio Ministério da Educação (BRASIL, 2015a) quanto o Conselho Nacional de Educação - CNE (BRASIL, 2015b) publicaram notas criticando a omissão nos Planos de Educação de açôes voltadas para a igualdade de gênero e o respeito à diversidade sexual. $\mathrm{O} C \mathrm{CNE}$ também afirma que "a ausência ou insuficiência de tratamento das referidas singularidades fazem com que os planos de educação que assim as trataram sejam tidos como incompletos e que, por isso, devem ser objeto de revisão" (BRASIL, 2015b).

No entanto, as pressões políticas por parte dos grupos de parlamentares fundamentalistas, têm feito com que o governo federal apenas recue. Exem- 
plo emblemático ocorreu em setembro de 2015, durante o ajuste fiscal e reforma administrativa do Governo Federal. Em 9 de setembro, foi assinada a Portaria no 916/2015, que instituiu o Comitê de Gênero, de caráter consultivo, no âmbito do Ministério da Educação, com a competência de

propor diretrizes e apresentar subsídios técnicos e políticos para a formulação, avaliação e aperfeiçoamento de políticas que visem à garantia do direito à educaçáo de qualidade, dentre outras açôes, projetos e programas educacionais, com a promoção dos direitos relacionados às questóes de gênero e o enfrentamento das diversas formas de preconceito, discriminação e violência (BRASIL, 2015c, grifos nossos).

Mediante pressão da Câmara dos Deputados à Presidência da República, em um espaço de apenas 12 dias, o Comitê de Gênero foi extinto e substituído por um Comitê de Combate à Discriminação. Da mesma forma que aconteceu com os Planos de Educação, a palavra gênero foi eliminada do texto da Portaria (BRASIL, 2015d).

Uma vez aprovadas as leis municipais e estaduais dos respectivos Planos de Educaçáo, ocorreu um movimento voltado para impedir que os estabelecimentos de educação abordassem na sala de aula as questóes de gênero debatidas durante a elaboraçáo dos Planos. Foi circulado por e-mail e veiculado em diversos sites um modelo de notificação extrajudicial para "os professores desta escola [...] para que, em caráter peremptório, se abstenham de apresentar, ministrar, ensinar, ou por outra forma, informar qualquer dos temas relativos a matéria descrita no preâmbulo desta ao meu filho", sob pena de processo. Os temas descritos no preâmbulo incluem "ideologia de gênero e outras propostas a serem objeto de apresentação para as crianças nas escolas, especificamente, sobre temas relacionados com comportamentos sexuais especiais (homossexualidade, bissexualidade, transsexualidade (sic), etc.)..." (PUGGINA, 2015).

Náo demorou muito para as notificaçóes extrajudiciais, reproduzidas ipsis litteris, começarem a ser entregues nas escolas, provocando intimidação entre os/as profissionais de educação.

\section{Considerações finais}

À guisa de uma moral dita "cristâ", as mulheres feministas e as pessoas LGBT se transformaram, na visão de quem prega contra a "ideologia de gênero", em uma força do mal, no inimigo, a ser combatido a qualquer custo. Para Ivone Gebara, "o inimigo é também uma criação nossa. O inimigo, dependendo da perspectiva, é o diferente, é aquele que me ameaça, que exige a partilha de luga- 
res, de poderes e de haveres. O inimigo é o diferente, transformado em inimigo" (GEBARA, 2008, p. 57).

A ampla disseminação da falsa premissa da "ideologia de gênero", vista como a desconstrução dos papéis de gênero tradicionais e, por consequência, da família, dentro dos ambientes educacionais, despertou uma espécie de pânico moral, retrocesso e demonização do "inimigo", quando o que se pretendia com a "promoção da igualdade [...] de gênero e de orientação sexual" era simplesmente contribuir para "a superação das desigualdades educacionais" (BRASIL, 2012d) que comprovadamente existem entre os gêneros, em consonância com as décadas de debates, acordos e políticas públicas estabelecidos democraticamente a fim de promover a equidade de gênero.

Os argumentos utilizados pelos que disseminaram a noção de ideologia de gênero na forma acima mencionada, de que se trata de "totalitarismo", "nazismo", "imposição", podem ser igualmente aplicados a seus "adeptos", uma vez que desejam impor a manutenção das desigualdades de gênero nas quais as meninas e mulheres ficam em situações inferiores aos meninos e homens, manipulando pessoas sem senso crítico por meio de uma ideologia fascista sem fundamento científico.

Criou-se uma falácia apelidada de "ideologia de gênero", que induziria à destruição da família "tradicional", à legalização da pedofilia, ao fim da "ordem natural" e das relaçôes entre os gêneros, e que nega a existência da discriminação e violência contra mulheres e pessoas LGBT comprovadas com dados oficiais e estudos científicos. Utilizou-se de desonestidade intelectual, formulando argumentos sem fundamentos científicos e replicando-os nas mídias sociais para serem engolidos e regurgitados pelos fiéis acríticos que os aceitam como verdades inquestionáveis. Utilizou-se também de uma espécie de terrorismo moral, atribuindo o status de demônio às pessoas favoráveis ao respeito à igualdade de gênero e diversidade sexual na educação, além de intimidar profissionais de educação com notificações extrajudiciais com ameaça de processo contra quem ousasse abordar esses assuntos na sala de aula. Criou-se um movimento para "apagar" o assunto gênero do currículo escolar. Utilizou-se de uma ideologia no sentido de uma "crença utilizada para o controle dos comportamentos coletivos", podendo ser "uma crença totalmente infundada" (ABBAGNANO, 2003, p. 533).

É necessário, sim, defender a igualdade de gênero, mas não a partir de uma ideologia deturpada disseminada pelas forças reacionárias no debate sobre os Planos de Educação. O que é preciso defender é a erradicação das iniquidades de gênero, que fazem uma distinçáo binária entre masculino e feminino, relegando o feminino a um plano inferior, estabelecendo papéis inflexíveis de gênero para o masculino e o feminino que apenas servem para reforçar as desigualdades, muitas vezes originados no patriarcado, ou uma "or- 
dem patriarcal de gênero" (SAFIOTTI, 2004, p. 136). É preciso promover uma ideologia de gênero em que masculino e feminino tenham condiçōes de estar em pé de igualdade, inclusive para combater as violências contra o gênero feminino, consideradas por alguns como inelutáveis ou inerentes à condição masculina (HUACUZ ELÍAS, 2011, p. 12). E é essencial que isso também ocorra no âmbito da educação, uma vez que a educação é o lócus a partir do qual pode acontecer a transformação da sociedade (FREIRE, 2006), embora o que se percebe no discurso dos que disseminam a falácia da ideologia de gênero é o que Bourdieu (1982) descreve como a escola reprodutora das desigualdades na sociedade.

Nesse sentido, para diluir o perigo social representado por determinados contingentes se deixarem ser manipulados e seguirem cegamente dogmas e crenças em desencontro com valores democráticos e com o direito à igualdade, é preciso que a educação avance no cumprimento de seu papel de preparar os/as estudantes para a cidadania, inclusive no que diz respeito ao desenvolvimento da capacidade de criticidade (BARTNIK, 2012, p. 129), rumo à promoção da cultura da paz, definida como "uma sociedade pautada nos valores de justiça social, igualdade entre os sexos, eliminação do racismo, tolerância religiosa, respeito às minorias, educação universal, equilíbrio ecológico e liberdade política." (BRASIL, 2015e, p. 6-7). Para isso, também é preciso desenvolver a capacidade de dialogar de forma civilizada com quem pensa diferente, a fim de superar as diferenças. Nesse debate também é importante a participação ativa de pessoas e setores de "meio de campo", inclusive do mundo acadêmico e das religióes, que possam contribuir com posicionamentos que apontem para a moderação dos extremismos e a convivência harmônica com as diferenças.

Por último, vale lembrar as consideraçóes dos Pioneiros da Educação Nova, em 1932, há mais de 80 anos, quando falavam do respeito no regime escolar aos princípios fundamentais da laicidade, dos direitos do indivíduo e da necessidade de adaptar a educação "à diversidade nascente de gostos e à variedade de aptidóes [...] nos adolescentes e que "representam as únicas forças capazes de arrastar o espírito dos jovens à cultura superior'” (MANIFESTO, 1932).

\section{Referências}

ABBAGnANO, N. Dicionário de filosofia. São Paulo: Martins Fontes, 2003.

BARTNIK. H.L. de S. Gestão educacional. Curitiba: InterSaberes, 2012.

BORRILlO, D. A homofobia. In: LIONÇO, T.; DINIZ, D. (orgs.) Homofobia e educação: um desafio ao silêncio. Brasília: Letras Livres, 2009. 
BOURDIEU, P. A reprodução: Elementos para uma teoria do sistema de ensino. Rio de Janeiro: Ed. Francisco Alves, 1982.

BRASIL. Lei n. 9.394, de 20 de dezembro de 1996. Estabelece as diretrizes e bases da educação nacional. Diário Oficial [da] República Federativa do Brasil, Brasília, DF, 23 dez. 1996. Disponível em: <http://www.planalto.gov.br/ccivil_03/Leis/L9394.htm>. Acesso em: 11 out. 2015.

Lei n. 11.340, de 7 de agosto de 2006. Cria mecanismos para coibir a violência doméstica e familiar contra a mulher, nos termos do $\$ 8^{\circ}$ do art. 226 da Constituição Federal, da Convenção sobre a Eliminação de Todas as Formas de Discriminação contra as Mulheres e da Convenção Interamericana para Prevenir, Punir e Erradicar a Violência contra a Mulher; dispóe sobre a criação dos Juizados de Violência Doméstica e Familiar contra a Mulher; altera o Código de Processo Penal, o Código Penal e a Lei de Execução Penal; e dá outras providências. Diário Oficial [da] República Federativa do Brasil, Brasília, DF, 8 ago. 2006a. Disponível em: <http://www.planalto.gov.br/ccivil_03/_ ato2004-2006/2006/lei/l11340.htm>. Acesso em: 11 out. 2015.

Presidência da República. Secretaria Especial de Políticas para as Mulheres. Plano Nacional de Politicas para as Mulheres. Brasília: Secretaria Especial de Políticas para as Mulheres, 2006b.

Constituiçáo da República Federativa do Brasil: texto constitucional promulgado em 5 de outubro de 1988, com as alteraçóes adotadas pelas Emendas Constitucionais no $\mathrm{s}$ 1/92 a 56/2007 e pelas Emendas Constitucionais de Revisão no s 1 a 6/94. Brasília: Senado Federal, Subsecretaria de Ediçóes Técnicas, 2008a.

Presidência da República. Secretaria Especial de Políticas para as Mulheres. II Plano Nacional de Políticas para as Mulheres. Brasília: Secretaria Especial de Políticas para as Mulheres, 2008b.

Ministério da Educação. Conferência Nacional da Educação Básica. Documento Final. Brasília: Presidência da República, Ministério da Educação, Secretaria Executiva, Secretaria Executiva Adjunta, Comissão Organizadora da Conferência Nacional da Educação Básica, 2008c.

Presidência da República. Secretaria Especial dos Direitos Humanos. Plano Nacional de Promoção da Cidadania e dos Direitos Humanos de LGBT. Brasília: Secretaria Especial dos Direitos Humanos, 2009.

Comissão Organizadora Nacional da Conferência Nacional de Educação. Documento Final. Brasília: Ministério da Educação, Secretaria Executiva, 2010.

Presidência da República. Secretaria de Direitos Humanos. Relatório sobre violência homofóbica no Brasil: ano de 2011/Secretaria de Direitos Humanos; Priscila Pinto Calaf, Gustavo Carvalho Bernardes e Gabriel dos Santos Rocha (orgs.). Brasília, DF : Secretaria de Direitos Humanos, 2012a.

. Conselho Nacional de Educação. Parecer no 8, de 6 de março de 2012. Aprova as Diretrizes Nacionais para a Educação em Direitos Humanos. Diário Oficial [da] República Federativa do Brasil, Brasília, DF, 30 mai. 2012b. Disponível em: <http://portal. mec.gov.br/index.php?option=com docman \&view=download \&alias=10389-pcp008 -12-pdf\&category slug=marco-2012-pdf\&Itemid=30192>. Acesso em: 18 out. 2015. 
Ministério da Educação. Conselho Nacional de Educação. Câmara de Educação Básica. Resolução n. 2, 30 de janeiro de 2012. Define Diretrizes Curriculares para o Ensino Médio. Diário Oficial [da] República Federativa do Brasil, Brasília, DF, 31 jan. 2012c.

Câmara dos Deputados. Comissão de Constituição e Justiça e de Cidadania. Redação Final. Projeto de Lei no 8.083-B de 2010. Aprova o Plano Nacional de Educação - PNE e dá outras providências. Brasília, DF, 16 out. 2012d. Disponível em: <http://www2.camara.leg.br/proposicoesWeb/prop mostrarintegra;jsessionid=7129 FE0836A78035A52415DA0D4A031F.proposicoesWeb2?codteor $=103$

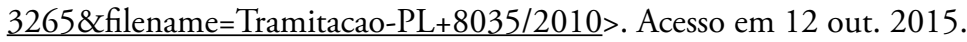

. Lei n. 12.852, de 5 de agosto de 2013. Institui o Estatuto da Juventude e dispóe sobre os direitos dos jovens, os princípios e diretrizes das políticas públicas de juventude e o Sistema Nacional de Juventude - SINAJUVE. Diário Oficial [da] República Federativa do Brasil, Brasília, DF, 8 ago. 2013a. Disponível em: <http://www.planalto.gov.br/ccivil_03/_ Ato2011-2014/2013/Lei/L12852.htm>. Acesso em: 14 out. 2015.

. Presidência da República. Secretaria de Políticas para as Mulheres. Plano Nacional de Politicas para as Mulheres. Brasília: Secretaria de Políticas para as Mulheres, 2013b.

Presidência da República. Secretaria de Direitos Humanos. Relatório sobre Violência Homofóbica no Brasil: o ano de 2012. Brasília, DF: Secretaria de Direitos Humanos, 2013c. Disponível em: <http://www.sdh.gov.br/assuntos/lgbt/pdf/ relatorio-violencia-homofobica-ano-2012>. Acesso em: 19 out. 2015

Senado Federal. Comissão Diretora. Parecer no 1.567, de 2013. Redação final do Substitutivo do Senado ao Projeto de Lei da Câmara no 103, de 2012 (no 8.035, de 2010, na Casa de origem). Brasília, DF, 17 dez. 2013d. Disponível em: <http://www25.senado. leg.br/web/atividade/materias/-/materia/108259>. Acesso em 12 out. 2015.

Lei n. 13.005, de 25 de junho de 2014. Aprova o Plano Nacional de Educação - PNE e dá outras providências. Diário Oficial [da] República Federativa do Brasil, Brasília, DF, 26 jun. 2014. Disponível em: <http://www.planalto.gov.br/ccivil 03/ ato2011-2014/2014/lei/113005.htm>. Acesso em: 14 out. 2015.

. Ministério da Educação. Secretaria de Educação Continuada, Alfabetização, Diversidade e Inclusão. Diretoria de Políticas de Educação em Direitos Humanos e Cidadania. Coordenação Geral de Direitos Humanos. Nota Técnica no 24/2015. Brasília: Ministério da Educação, 2015a. Disponível em: <http://www.spm.gov.br/ assuntos/conselho/nota-tecnica-no-24-conceito-genero-no-pne-mec.pdf $>$. Acesso em: 17 out. 2015.

. Conselho Nacional de Educação. Nota Pública às Assembleias Legislativas, à Câmara Legislativa do DF, às Câmaras de Vereadores, aos Conselhos Estaduais, Distrital e Municipais de Educação e à Sociedade Brasileira, de $1^{\circ}$ de setembro de 2015. Brasília: Conselho Nacional de Educação, 2015b. Disponível em: <http://www.cnte.org.br/ index.php/comunicacao/noticias/15472-nota-publica-as-assembleias-legislativas-acamara-legislativa-do-df-as-camaras-de-vereadores-aos-conselhos-estaduais -distrital-e-municipais-de-educacao-e-a-sociedade-brasileira.html $>$. Acesso em 17 out. 2015. 
Ministério da Educação. Portaria no 916, de 9 de setembro de 2015. Institui Comitê de Gênero, de caráter consultivo, no âmbito do Ministério da Educação. Diário Oficial [da] República Federativa do Brasil, Brasília, DF, 10 set. 2015c. Disponível em: <https://www.capes.gov.br/images/stories/download/legislacao/109 2015-PORTARIA-MEC-N-916-de-992015.pdf >. Acesso em: 18 out. 2015.

Ministério da Educação. Portaria no 949, de 21 de setembro de 2015. Institui Comitê de Combate à Discriminação, de caráter consultivo, no âmbito do Ministério da Educação. Diário Oficial [da] República Federativa do Brasil, Brasília, DF, 22 set. 2015d. Disponível em: shttp://portal.mec.gov.br/index.php?option=com docman\&view= download\&alias=21381-port-948-educ-campo-22-9-15-pdf\&Itemid=30192>. Acesso em: 18 out. 2015 .

Ministério da Saúde. Secretaria-Executiva. Subsecretaria de Assuntos Administrativos. Reflexóes sobre a cultura de paz e não violência no trabalho. Brasília: Ministério da Saúde, 2015e.

DE OLHO NOS PLANOS. Maioria dos planos estaduais de educação aprovados incluem referência à igualdade de gênero. Disponível em: <http://www.deolhonosplanos.org.br/ maioria-dos-planos-estaduais-de-educacao-aprovados-incluem-referencia-a-igualdade-degenero/>. Acesso em: 31 jan. 2016.

FREIRE, P. Pedagogia da autonomia. São Paulo: Paz e Terra, 2006.

GEBARA, I. O que é cristianismo. São Paulo: Brasiliense, 2008.

HUACUZ ELÍAS, M.G. La bifurcación del caos. Reflexiones sobre el concepto de violencia falocéntrica desde el método de la complejidad. México: Universidad Autónoma Metropolitana-Xochimilco, 2011.

MANIFESTO DOS PIONEIROS DA EDUCAÇÃO NOVA. 1932. Disponível em: <http://www.histedbr.fe.unicamp.br/revista/edicoes/22e/doc1 22e.pdf $>$. Acesso em 24 out. 2015 .

MARX, K; ENGELS, F. A Ideologia Alemã. São Paulo: Martins Fontes, 1997.

MAZZON, J.A. (Org.). Principais resultados: projeto de estudo sobre açóes discriminatórias no âmbito escolar, organizadas de acordo com áreas temáticas, a saber, étnico-racial, gênero, geracional, territorial, necessidades especiais, socioeconômica e orientação sexual. São Paulo: Fundação Instituto de Pesquisas Econômicas, Ministério da Educação, Instituto Nacional de Estudos e Pesquisas Educacionais, 2009. Disponível em: <http://www.abglt.org.br/port/pesquisas.php $>$. Acesso em: 19 out. 2015.

MICHAELIS. Moderno dicionário da lingua portuguesa. São Paulo: Companhia Melhoramentos, 1998 (Dicionários Michaelis).

OEA - Organização dos Estados Americanos. Convenção Interamericana para Prevenir, Punir e Erradicar a Violência contra a Mulher (Convenção de Belém do Pará). 1994. Disponível em: $\leq$ http://www.cidh.org/Basicos/Portugues/m.Belem.do.Para.htm $>$. Acesso em: 11 out. 2015. 
. AG/RES. 2435 sobre Derechos Humanos, Orientación Sexual e Identidad de Género. 2008. Disponível em: <https://www.oas.org/dil/esp/AG-RES 2435 XXXVIII-O-08. pdf $>$. Acesso em: 11 out. 2015.

ONU - Organização das Naçóes Unidas. Declaração Universal dos Direitos Humanos. 1948. Disponível em: <http://unesdoc.unesco.org/images/0013/001394/139423por.pdf >. Acesso em: 11 out. 2015.

. Joint Statement No. A/63/635 on Human Rights, Sexual Orientation and Gender Identity. 2008. Disponível em: shttp://www.hirschfeld-eddy-stiftung.de/fileadmin/ images/dokumente/virtuelle bibliothek/UN document 63635 Eng.pdf $>$. Acesso em: 11 out. 2015.

PNUD - Programa das Naçóes Unidas para o Desenvolvimento. Objetivos do Desenvolvimento Sustentável. 2015. Disponível em: <http://www.itamaraty.gov.br/images/ ed desenvsust/20150819-CGDES-ODS-port.pdf>. Acesso em: 11 out. 2015.

PRINCÍPIOS de Yogyakarta. Princípios sobre a aplicação da legislação internacional de direitos humanos em relação à orientaçâo sexual e identidade de gênero. 2007. Disponível em: $\leq$ http:// www.dhnet.org.br/direitos/sos/gays/principios de yogyakarta.pdf $>$. Acesso em: 19 out. 2015.

PUGGINA Conservadores e Liberais. Proteja seus filhos da ideologia de gênero. 12 out. 2015. Disponível em: <http://www.puggina.org/fique-sabendo/proteja-seus-filhos-daideologia-de-genero/208>. Acesso em: 13 out. 2015.

RIFAN, F.A. A ideologia de gênero. Disponível em: <http://www.cnbb.org.br/outros/domfernando-areas-rifan/16673-a-ideologia-de-genero $>$. Acesso em: 13 out. 2015.

SAFFIOTI, H.I.B. Gênero, patriarcado, violência. $1^{\text {a }}$ ed. São Paulo: Fundação Perseu Abramo, 2004.

SCALA, J. Ideologia de Gênero: o neototalitarismo e a morte da família. Zenit. 31 jan. 2012. Disponível em: $\leq$ https://pt.zenit.org/articles/ideologia-de-genero-neototalitarismoe-a-morte-da-fami-lia/>. Acesso em: 20 set. 2015.

. Ideologia de Gênero: o neototalitarismo e a morte da família. 2. ed. Trad. Lyège Carvalho. São Paulo: Katechesis, 2015.

SCHERER, O. Educação e questão de gênero. O Estado de São Paulo. Sáo Paulo. 13 jun. 2015. Disponível em: <http://opiniao.estadao.com.br/noticias/ geral,educacao-e--questao-de-genero,1705540>. Acesso em: 19 out. 2015.

TRANSGENDER EUROPE. 2015. Disponível em: <http://tgeu.org/tmm-idahotupdate-2015/>. Acesso em: 16 abr. 2016.

UNESCO - Organização das Nações Unidas para a Educação, a Ciência e a Cultura. Educação para Todos: o compromisso de Dakar. Brasília: UNESCO, CONSED, Ação Educativa, 2001. 70 p. Disponível em: <http://unesdoc.unesco.org/ images/0012/001275/127509porb.pdf>. Acesso em 13 out. 2015.

UNFPA - Fundo de População das Naçóes Unidas. Declaração e Plataforma de Ação da IV Conferência Mundial sobre a Mulher. Pequim, 1995. Disponível em: $\leq$ http://www.unfpa. org.br/Arquivos/declaracao beijing.pdf>. Acesso em: 11 out. 2015. 
UNICEF - Fundo das Naçóes Unidas para a Infância. Convenção sobre a Eliminação de Todas as Formas de Discriminação Contra as Mulheres. 1979. Disponível em: <http://www. unicef.org/brazil/pt/resources 10233.htm>. Acesso em: 11 out. 2015.

UNITED NATIONS OFFICE OF THE HIGH COMMISSIONER FOR HUMAN RIGHTS. Nascidos livros e iguais: orientaçáo sexual e identidade de gênero no regime internacional de direitos humanos. Nova York e Genebra, 2012, Brasília, 2013. Disponível em <http://www.ohchr.org/Documents/Publications/BornFreeAndEqualLowRes Portuguese. pdf>. Acesso em: 11 out 2015.

WAISELFISZ, J.J. Mapa da Violência 2015: homicídios de mulheres no Brasil. Flacso Brasil. 2015. Disponível em: <http://www.mapadaviolencia.org.br/pdf2015/ MapaViolencia 2015 mulheres.pdf $>$. Acesso em: 18 jun. 2015.

Recebido em 20 de junho de 2016.

Aprovado em 15 de setembro de 2016. 